\title{
Correction to: Establishing a Reproducible Murine Animal Model of Single Anastomosis Duodenoileal Bypass with Sleeve Gastrectomy (SADI-S)
}

\author{
Laura Montana $^{1} \cdot$ Mylene Lamon $^{2} \cdot$ Christophe Barrat $^{1} \cdot$ Boris Hansel $^{3} \cdot$ Christophe Magnan $^{2} \cdot$ Konstantinos Arapis $^{4}$
}

Published online: 15 May 2018

(C) The Author(s) 2018

\section{Correction to: Obesity Surgery}

https://doi.org/10.1007/s11695-018-3254-4

The first and last names of the authors were inverted in the original article. They are displayed correctly here.

The online version of the original article can be found at https://oi.org/ 10.1007/s11695-018-3254-4

Christophe Magnan

christophe.magnan@univ-paris-diderot.fr

Laura Montana

doc.laura.montana@gmail.com

Mylene Lamon

mylene.lamon@gmail.com

Christophe Barrat

chtistophe.barrat@aphp.fr

Boris Hansel

boris.hansel@aphp.fr

Konstantinos Arapis

konstarapis@hotmail.com
Department of Digestive and Metabolic Surgery, Centre Intégré Nord Francilien de l'Obésité, University Hospital Avicenne, 125 rue de Stalingrad, Bobigny, 93000 Paris, France

2 Team of Regulation of Glucose Homeostasis by Nervous System (REGLYS), University of Paris (7) Diderot-CNRS UMR8251, Bâtiment Buffon, 3ème étage, pièce 340A, case courrier 7126, 4 rue Marie Andrée Lagroua Weill-Halle, 75205 Paris Cedex 13, France

3 Department of Diabetes and Nutrition, Bichat-Claude Bernard University Hospital, 46, rue Henri Huchard, 75877 Cedex 18 Paris, France

4 Department of General and Digestive Surgery, University Hospital Bichat-Claude Bernard, 46, rue Henri Huchard, 75877 Cedex 18 Paris, France 